\title{
Behavioral changes in calves 11 days after cautery disbudding: Effect of local anesthesia
}

\author{
Sarah J. J. Adcock, ${ }^{1,2} \odot$ Danielle M. Cruz, ${ }^{1}$ and Cassandra B. Tucker ${ }^{1 *}$ (]) \\ ${ }^{1}$ Center for Animal Welfare, Department of Animal Science, University of California, Davis 95616 \\ ${ }^{2}$ Animal Behavior Graduate Group, University of California, Davis 95616
}

\begin{abstract}
Hot-iron disbudding results in painful burn wounds that take weeks to heal. Spontaneous behaviors indicative of pain are apparent in the immediate hours after disbudding, but whether they occur later in the healing process is unknown. To evaluate whether ongoing pain was present around the time the necrotic tissue loosens from the scalp, we tested the effect of administration of local anesthetic $11 \mathrm{~d}$ after the procedure. Disbudded female Holstein and Jersey calves $(\mathrm{n}=24)$ were randomly assigned to receive an injection of local anesthetic (lidocaine) or saline at the cornual nerve on both sides of the head. We recorded the frequency of 8 behaviors for 75 min: head shakes, head rubs, head scratches, ear flicks, tail flicks, bucks/jumps/kicks, grooming, and transitions between standing and lying. Calves treated with lidocaine shook their heads less and tended to flick their ears less than calves administered saline, consistent with the effects of pain relief previously reported in the immediate hours after disbudding. These calves also rubbed their head against the sides of the pen more often, suggesting lidocaine suppressed wound protective behavior. Head shaking and head scratching became more common in the last 25 min compared with the first $50 \mathrm{~min}$ in calves treated with lidocaine, consistent with the return of sensation to the disbudding wounds. No treatment differences in the other behaviors were observed. These results suggest that calves experience ongoing pain $11 \mathrm{~d}$ after hot-iron disbudding, adding to a growing body of evidence that pain persists for weeks after the procedure.
\end{abstract}

Key words: dairy cattle, pain, hot-iron disbudding, animal welfare

\section{INTRODUCTION}

Hot-iron disbudding is a standard procedure on dairies to prevent horn growth in calves (USDA, 2018).

Received February 9, 2020.

Accepted April 4, 2020.

*Corresponding author: cbtucker@ucdavis.edu
The horn-producing cells are destroyed via cauterization, resulting in burn wounds that take 6 to 13 wk to re-epithelialize and are painful to mechanical stimulation throughout that time (Adcock and Tucker, 2018a; Adcock et al., 2019; Casoni et al., 2019). Calves may also experience ongoing pain in the absence of external stimulation during the healing period (Adcock and Tucker, 2018b). Ongoing pain has been assessed using operant behavior; calves will pay a cost to access analgesia $3 \mathrm{wk}$ after disbudding, suggesting that calves experience ongoing pain far longer than previously assumed (Adcock and Tucker, 2020). To our knowledge, no studies have evaluated whether disbudded calves spontaneously show behaviors indicative of ongoing pain during the healing period.

Spontaneous behaviors, including head shaking, head rubbing, head scratching, and ear flicking, increase in the immediate hours after hot-iron disbudding, and are dampened by local anesthesia and nonsteroidal antiinflammatory drugs (Grondahl-Nielsen et al., 1999; Heinrich et al., 2010; Stilwell et al., 2012; Huber et al., 2013). Other behavioral changes have been observed after hot-iron disbudding, but have not yet been replicated in other studies, including more tail flicks (Heinrich et al., 2010), less bucking (Mintline et al., 2013), less grooming, and more transitions between lying and standing (Morisse et al., 1995) compared with sham controls or calves disbudded with pain relief. It is unknown whether these effects persist during the healing period, as spontaneous behavioral changes have only been measured up to $44 \mathrm{~h}$ after the procedure (Heinrich et al., 2010). Although most studies find behavioral differences dissipate within the first $24 \mathrm{~h}$, it is possible that pain fluctuates over the course of healing (Adcock and Tucker, 2018b). Indeed, burn pain in humans can worsen unpredictably over time before the wound heals (Summer et al., 2007).

Around the second week after bud-in cautery disbudding, the initial necrotic cap begins to detach from the scalp (Adcock and Tucker, 2018a). To evaluate whether ongoing pain was present around this healing phase, we tested whether spontaneous behaviors were altered in dairy calves receiving a cornual nerve block with lido- 
caine $11 \mathrm{~d}$ after disbudding. We predicted that calves treated with lidocaine would exhibit fewer head shakes, head scratches, head rubs, ear flicks, tail flicks, and transitions, and more bucks/jumps/kicks and grooming than calves given saline, and that these differences would reverse as the anesthesia wore off and painful sensation returned to the wounds.

\section{MATERIALS AND METHODS}

Data were collected from July to October 2018 at the University of California, Davis Dairy Teaching and Research Facility. All procedures were approved by the Institutional Animal Care and Use Committee (Protocol \#20505).

\section{Animal Husbandry and Housing}

Female Holstein $(\mathrm{n}=19)$ and Jersey $(\mathrm{n}=5)$ calves were 24 to $38 \mathrm{~d}$ of age at the start of the experiment. We used all available female calves born between June 10 and September 1, 2018. Our sample size was determined by the availability of animals at the facility during this period. Calves were individually housed in outdoor wire-fenced enclosures $(2.0 \mathrm{~m}$ long $\times 1.5 \mathrm{~m}$ wide $\times 0.9 \mathrm{~m}$ high $)$ with an attached plastic hutch $(2.0$ $\mathrm{m}$ long $\times 1.5 \mathrm{~m}$ wide $\times 1.3 \mathrm{~m}$ high) and sand bedding (approximately 15-20 $\mathrm{cm}$ deep).

Calves were bottle-fed milk replacer $(26 \% \mathrm{CP}$ and $16 \%$ fat, $15 \%$ total solids; Calva Products Inc., Acampo, $\mathrm{CA}$ ) at 0645,1245 , and $1845 \mathrm{~h}$. At each meal, Holsteins were fed $2.8 \mathrm{~L}$. Jerseys were fed $2.4 \mathrm{~L}$ of milk replacer from 24 to $30 \mathrm{~d}$ of age, which then increased to $2.8 \mathrm{~L}$ from $31 \mathrm{~d}$ on. At $38 \mathrm{~d}$, Jerseys were transitioned to bucket feeding. Water and starter $(18.3 \%$ CP, $2.8 \%$ fat, $4 \%$ crude fat; Associated Feed \& Supply Co., Turlock, CA) were provided ad libitum in buckets. As part of a separate concurrent study, 8 calves ( 4 from the lidocaine treatment, 4 from the saline treatment) received chopped mountain grass hay (34\% CP) ad libitum.

\section{Disbudding}

All calves were disbudded between 24 and $38 \mathrm{~d}$ of age (mean age \pm SD: $31 \pm 4 \mathrm{~d}$ ). For the disbudding procedure, we placed the calf in a head restraint in the home pen, as depicted in Jimenez et al. (2019). An injection of $5.5 \mathrm{~mL}$ buffered $2 \%$ lidocaine hydrochloride was administered subcutaneously with a 20-gauge $x$ 25 -mm needle on each side of the head to produce a cornual nerve block. To buffer the lidocaine, we added $8.4 \%$ sodium bicarbonate to the lidocaine in a $1: 10$ ratio immediately before administering the injection. We assessed numbness 10 min after the injections by pressing a needle around the base of each horn bud. If the calf moved her head in response to any of the pricks, we gave an additional $2.2 \mathrm{~mL}$ buffered lidocaine. A 5- to $7-\mathrm{cm}^{2}$ patch of hair was clipped over each horn bud using an electric razor with a 40 blade. An electric cautery iron (Rhinehart X50, Rhinehart Development Corp., Spencerville, IN) with a 1.3-cm tip was applied to each horn bud until a uniform copper-colored ring formed (mean duration of application/bud $\pm \mathrm{SD}=18$ $\pm 5 \mathrm{~s}$; mean iron temperature $\pm \mathrm{SD}=437 \pm 20^{\circ} \mathrm{C}$ ). We did not remove the horn bud (bud-in approach). Immediately after disbudding, the calf received a gelatin capsule (1/8 oz., Torpac, Fairfield, NJ) containing 7.5-mg meloxicam tablets dosed at $1 \mathrm{mg} / \mathrm{kg}$.

\section{Treatments}

We assigned calves to 1 of 2 treatments $11 \mathrm{~d}$ after disbudding: cornual nerve block of both horn buds with buffered lidocaine $(\mathrm{n}=13)$ or saline as a control (n $=11$ ). Treatments alternated between calves based on birth order, but within this approach were also balanced by breed and age at disbudding. The same person (S.J.J.A.) determined the treatment order and enrolled calves in the study. Before receiving the injections, calves were restrained in the home pen with the head restraint and blindfolded, as this appears to calm them (S.J.J.A, personal observation). The first 5 calves (3 lidocaine, 2 saline) received $6.6 \mathrm{~mL}$ on each side, however this yielded insufficient nerve blocks, so we increased our initial amount to $8.8 \mathrm{~mL}$ for the remaining calves. Injections were administered subcutaneously on each side of the head with a 20 -gauge $\times 25$-mm needle between 1600 and $1700 \mathrm{~h}$. Calves were released from the head restraint for $10 \mathrm{~min}$, and then restrained again for a pin-prick test. If a calf that received lidocaine responded, we administered an additional $2.2 \mathrm{~mL}$ before releasing her from the head restraint. We used a pen cap instead of a needle for the pinprick test in controls. Behavioral data were collected for $75 \mathrm{~min}$, beginning immediately after the calf was released. After this time, she was restrained for a pin-prick test to determine the extent to which anesthesia was still present. We pressed a needle around each horn bud in 8 evenly spaced locations. Pin-prick tests were scored from 0 to 8 depending on the number of responses in the form of sudden head movements. We assigned a score of 0 if no behavioral responses were elicited, and 8 if the calf responded to all pinpricks.

\section{Data Collection}

Behavior. Calves were video recorded for $75 \mathrm{~min}$ following the first pin-prick test. Up to 4 calves were 
Table 1. Ethogram used to code behavior $11 \mathrm{~d}$ after disbudding in calves receiving cornual nerve injections with lidocaine or saline

\begin{tabular}{ll}
\hline Behavior & Definition \\
\hline Head scratch & $\begin{array}{l}\text { Hoof of hind leg is in contact with head. To count as a new scratch, the hoof must first come in contact with the } \\
\text { ground. }\end{array}$ \\
Head rub & $\begin{array}{l}\text { Head is in contact with an object, moving in a repetitive motion either forward and backward or side-to-side. There } \\
\text { must be at least } 1 \mathrm{~s} \text { between object contact to count as a new head rub. } \\
\text { The calf rotates her head at least once to both sides (left and right) in rapid succession. To count as a new head } \\
\text { shake, the head must return to a resting position. }\end{array}$ \\
Head shake & $\begin{array}{l}\text { One or both ears move at least once back and forth in rapid succession. To count as a new ear flick, the ears must } \\
\text { return to a resting position. Flicks are independent of head shakes. }\end{array}$ \\
Ear flick & $\begin{array}{l}\text { Tail crosses the midline of either rear leg in an outwards and upwards motion at least } 1 \text { time. To count as a new } \\
\text { tail flick, the tail must return to a resting position. Tail movement associated with urination and defecation are not } \\
\text { Tail flick }\end{array}$ \\
included. & $\begin{array}{l}\text { Both hind legs or both forelegs are lifted off the ground or } 1 \text { hind leg is lifted off the ground and extended away from } \\
\text { the body. }\end{array}$ \\
Touching hair with the tongue or mouth on calf's own body. & Calf goes from standing (weight borne by hooves) to lying (body contact with ground) or vice versa. \\
Grooming &
\end{tabular}

recorded at one time (2 HC-V180, 1 HC-V550, 1 HCV160, Panasonic, Kadoma, Japan). We placed each camcorder on a tripod $1.5 \mathrm{~m}$ high, approximately 1.2 $\mathrm{m}$ in front of the home pen. A single observer, blind to treatment, coded video for 8 behaviors (Table 1) using Behavioral Observation Research Interactive Software (BORIS, http://www.boris.unito.it/; Friard and Gamba, 2016). We calculated intra-rater reliability from 15-min video segments of 5 calves (intraclass correlation coefficient $\geq 0.98$ ).

Photography. Digital photographs of the disbudding wounds were taken with a digital single-lens reflex camera (D5300; Nikon, Tokyo, Japan) when the calf was in the head restraint, immediately following the injection, and again at the end of the 75-min period to allow comparison of the wound over this time. Photos were taken $15 \mathrm{~cm}$ from the wound. One person, blind to treatment, scored the photos for tissues present in the wound bed, using definitions in Adcock and Tucker (2018a). Photos were not taken for the first 5 calves (3 lidocaine, 2 saline), as this measure was added after we observed that some calves had exacerbated their wounds during data collection.

\section{Statistical Analysis}

Based on visual inspection of the data, we divided the $75 \mathrm{~min}$ of observation into 2 periods: 0 to $50 \mathrm{~min}$ $(0-3,000 \mathrm{~s})$ and 50 to $75 \mathrm{~min}(3,001-4,500 \mathrm{~s})$. We tested the effect of treatment, period, and their interaction on counts of each behavior, using generalized linear mixed models. We visually inspected residuals versus fits plots to confirm homogeneity of variance. Variables that were overdispersed (head scratches, head shakes, ear flicks, tail flicks, grooming) were fitted with a negative binomial distribution. Transitions and head rubs were not overdispersed and so were fitted with a Poisson dis- tribution. Bucks/jumps/kicks were too rare to warrant statistical analysis. Calf was included as a random effect in all the models. We included the log of the period duration (50 or $25 \mathrm{~min}$ ) as an offset variable. Models were fitted with the glmmADMB package in $\mathrm{R}$, version 3.4.2. (R Core Team, 2017). When an interaction effect was present $(P<0.10)$, we calculated pairwise contrasts using Tukey's method with the emmeans package (Lenth, 2018). Data are available online in the Dryad repository (https://doi.org/10.25338/B8PP77).

\section{RESULTS}

\section{Behavior}

Figure 1 depicts the frequency of behaviors during the 0 - to 50-min and 50- to 75-min observation periods. Calves that received lidocaine rubbed their heads more $\left(\chi^{2}{ }_{1}=5.83 ; P=0.016\right)$ and tended to flick their ears less $\left(\chi^{2}{ }_{1}=2.95 ; P=0.086\right)$ than calves that received saline, regardless of period (Figure 1).

We observed an interaction between period and treatment for head shaking $\left(\chi^{2}{ }_{1}=9.98, P=0.002\right)$ and head scratching $\left(\chi_{1}^{2}=3.11 ; P=0.078\right)$. Pairwise comparisons are shown in Figure 1.

We observed no effect of treatment, period, or their interaction on the frequency of transitions $\left(\chi^{2}{ }_{1} \leq 2.08\right.$; $P \geq 0.149)$ or grooming $\left(\chi_{1}^{2} \leq 1.46 ; P \geq 0.228\right)$. Tail flicking was higher in the last 25 min compared with the first $50 \mathrm{~min}$, regardless of treatment $\left(\chi^{2}{ }_{1}=4.05, P\right.$ $=0.044)$.

\section{Pin-Prick Test}

Of the 13 calves that received lidocaine, 6 required a second injection to numb the horn bud before the start 
of the observation period. After the 75-min observation period, $31 \%$ of wounds were fully desensitized, $21 \%$ were fully sensitized, and $46 \%$ were partially desensitized (1-7 pin-prick responses).

\section{Wound Scoring}

Calves in both treatments had similar wound tissue profiles before the observation period. No changes in

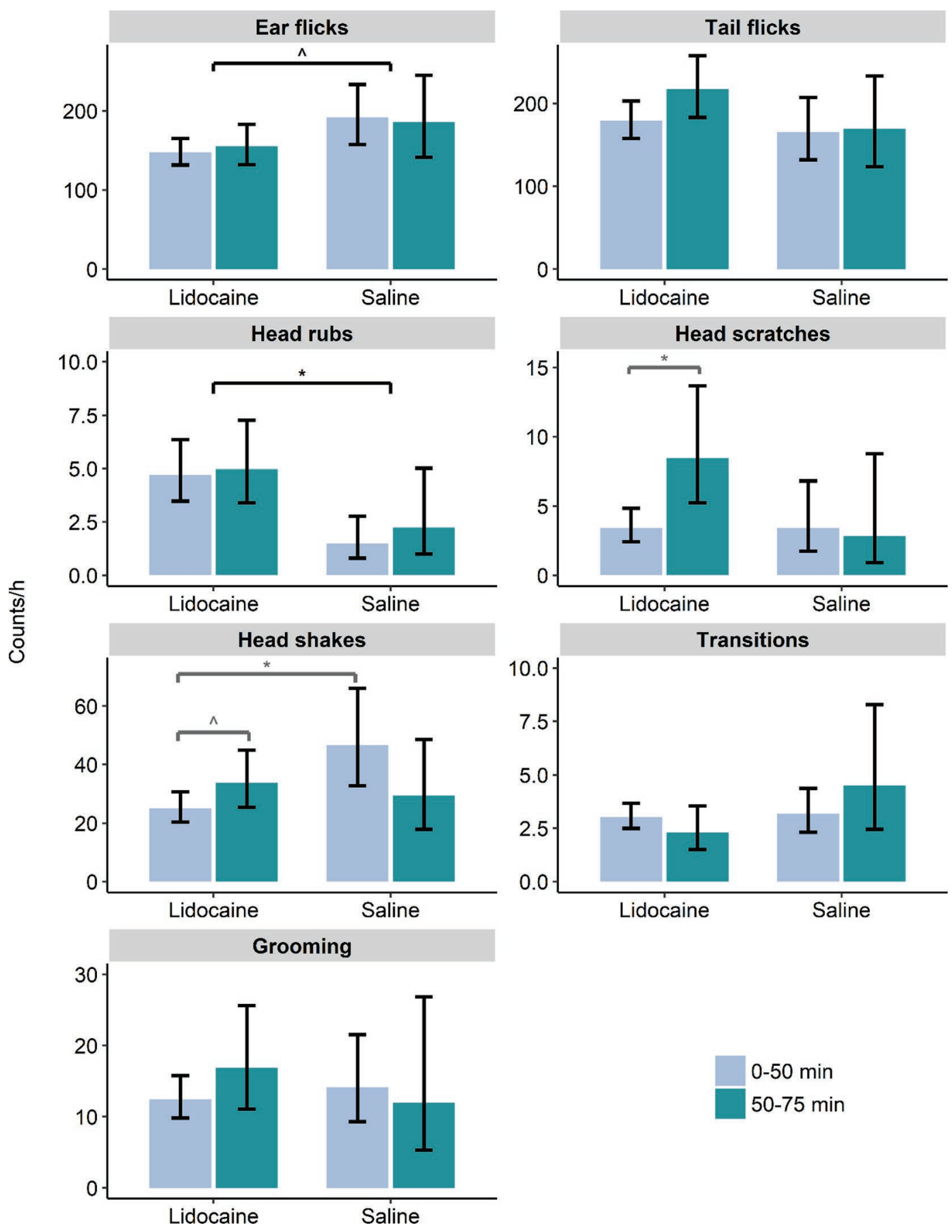

Figure 1. Behaviors as mean counts per hour $\pm \mathrm{SE}$, divided into 2 periods: 0-50 min and 50-75 min. Calves received cornual nerve injections with lidocaine or saline 0 to 15 min before behavioral observation. For ease of interpretation, values are presented as rates for a 1-h period and are back-transformed from the log scale. Behaviors are defined in Table 1. Main treatment effects and pairwise comparisons, following a significant treatment $\times$ period effect, are shown in black and gray brackets, respectively. ${ }^{*} P \leq 0.030 ;{ }^{\wedge} 0.074 \leq P \leq 0.086$. 

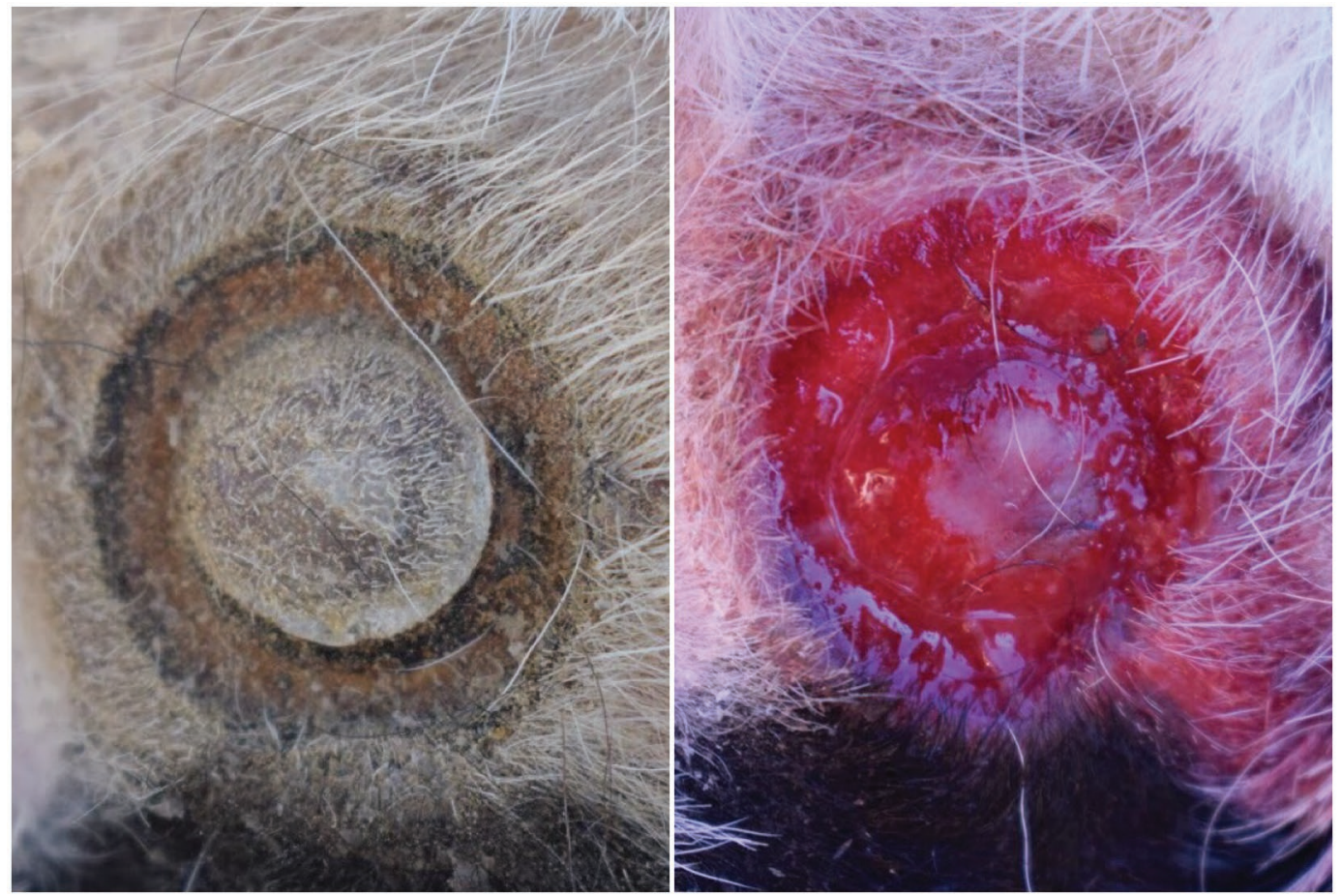

Figure 2. A wound $11 \mathrm{~d}$ after disbudding, before (left) and after (right) the necrotic tissue was scratched or rubbed off in the 75 min following the lidocaine cornual nerve block.

tissues were present before and after calves received saline. Of the 20 wounds photographed in calves treated with lidocaine, the necrotic tissue was initially attached in 15 and detaching in 5. By the end of the observation period, the necrotic tissue was attached in 11 wounds, detaching in 7 , and had completely fallen off in 2 (Figure 2). In addition, exudate, which was seen in only 1 wound initially, was present in 7 wounds at the end of the observation period (Table 2).

\section{DISCUSSION}

Calves treated with lidocaine had $46 \%$ fewer head shakes and $20 \%$ fewer ear flicks following injections compared with controls administered saline. This reduction in movement is consistent with provision of pain relief at the time of and in the hours after hot-iron disbudding. For example, calves that receive lidocaine before hot-iron disbudding show comparable reductions in head shaking and ear flicking in the immediate hours after the procedure compared with calves disbudded without pain relief (Morisse et al., 1995; Graf and Senn, 1999; Grondahl-Nielsen et al., 1999; Stilwell et al., 2012). Nonsteroidal anti-inflammatory drug administration also results in fewer head shakes and ear flicks compared with disbudding with lidocaine alone (Faulkner and Weary, 2000; Heinrich et al., 2010). The similar behavioral changes observed after provision of pain relief at the time of or $11 \mathrm{~d}$ after hot-iron disbudding support a growing body of evidence that calves continue to experience pain in the weeks after the procedure (Adcock and Tucker, 2018a; Casoni et al., 2019; Adcock and Tucker, 2020).

Although calves given pain relief performed less head shaking and ear flicking, they also rubbed their heads more than controls. Calves experiencing pain may en-

Table 2. The percentage of wounds in which tissue types were present $11 \mathrm{~d}$ after disbudding in calves $(\mathrm{n}=19$ photographed) receiving cornual nerve injections with lidocaine (20 wounds) or saline (18 wounds) ${ }^{1}$

\begin{tabular}{llccc}
\hline Treatment & $\begin{array}{l}\text { Relation to } \\
\text { observation period }\end{array}$ & $\begin{array}{c}\text { Attached } \\
\text { necrotic }\end{array}$ & $\begin{array}{c}\text { Detaching } \\
\text { necrotic }\end{array}$ & Exudate \\
\hline Lidocaine & Before & 75 & 25 & 5 \\
Lidocaine & After & 55 & 35 & 35 \\
Saline & Before & 61 & 39 & 6 \\
Saline & After & 61 & 39 & 6 \\
\hline
\end{tabular}

${ }^{1}$ Wounds were scored before the observation period and again 75 min later. 
gage in more head shaking and ear flicking to activate low-threshold mechanoreceptors that reduce transmission of pain impulses, according to gate-control theory (Melzack, 1996). In contrast, calves administered lidocaine may have been more willing to rub their heads, triggering activity in the sensitized nociceptive nerves, because they were numb and protective responses were suppressed. Indeed, the more head rubs in calves administered lidocaine compared with controls likely explains the increase in detaching necrotic tissue and exudate during the observation period, consistent with the idea that lidocaine suppressed the protective role of pain. In accordance with this theory, calves reduced rubbing their head on objects or pushing it against penmates, in the first $4 \mathrm{~h}$ after hot-iron disbudding without local anesthesia (Morisse et al., 1995; Graf and Senn, 1999). However, despite these early findings, subsequent studies observed either no change in time spent rubbing or touching the head against objects or penmates after hot-iron disbudding (Doherty et al., 2007; Mintline et al., 2013; Bates et al., 2019), or have reported more head rubbing in calves disbudded with a hot-iron (Faulkner and Weary, 2000; Heinrich et al., 2010; Stilwell et al., 2012; Huber et al., 2013) or caustic paste (Vickers et al., 2005; Stilwell et al., 2009) compared with non-disbudded calves. Interestingly, however, all the studies that reported more head rubbing defined the behavior entirely or in part as scratching with the hindfeet. Thus, it appears that these studies were measuring a different behavioral response than we were, and highlight the caution needed when broadly defining head-related behaviors as pain indicators for disbudding.

Alternatively, or additionally, it is possible that the increased head rubbing in calves receiving lidocaine reflected an attempt to relieve possible abnormal sensations (i.e., hypoesthesia or paresthesia) induced by potential mechanical or chemical nerve injury from the drug (Moon et al., 2012). In agreement with this interpretation, Vickers et al. (2005) reported increased head rubbing, which also included head scratching, in calves sham-disbudded with xylazine and lidocaine compared with sham calves given only the sedative. Sham-disbudded calves will choose a context paired with a saline injection over one paired with lidocaine, suggesting that the drug itself is aversive (Adcock and Tucker, 2020). Indeed, lidocaine is known to cause pain when injected in humans (Cepeda et al., 2010). A reduction in play has been observed $3 \mathrm{~h}$ after a lidocaine cornual nerve block in sham-disbudded calves, which may indicate continued discomfort at the injection sites after the anesthesia has worn off (Mintline et al., 2013). However, Bates et al. (2019) found no differences in head shaking, head scratching, or head rubbing in the
$3 \mathrm{~h}$ after lidocaine injection in sham-disbudded calves compared with non-injected controls. Further research is warranted on the physiological and affective consequences of lidocaine.

Head scratches and head shakes increased in the 50to 75 -min observation period, presumably indicating a return of sensation to the horn bud area. Indeed, $69 \%$ of wounds had regained partial or full sensation at the end of the observation period (approximately $90 \mathrm{~min}$ after administration of the initial pair of cornual nerve blocks, and 75 min after the second pair, if the first was unsuccessful). The increase in these behaviors as the drug wore off suggests that the wounds were painful 11 d after disbudding. In support of this interpretation, when the anesthetic effect subsides after disbudding or dehorning, cortisol (McMeekan et al., 1998; Stilwell et al., 2009), heart rate (Stewart et al., 2009), and spontaneous behaviors (Graf and Senn, 1999; Sylvester et al., 2004; Stilwell et al., 2012) rise above levels documented in calves that did not receive local anesthesia. Importantly, the changes that occur as lidocaine wears off are only observed in disbudded or dehorned calves; sham controls given lidocaine do not show increased behavioral (Graf and Senn, 1999; McMeekan et al., 1999; Faulkner and Weary, 2000) or physiological (Sutherland et al., 2002; Stewart et al., 2009) responses at the time sensation is thought to be restored. Thus, the delayed increase in head scratching and head shaking likely reflects the return of nociception to the wounded area as the anesthesia subsides, suggesting that ongoing pain is present in the weeks after disbudding.

The lack of a treatment effect on tail flicks, transitions, and grooming is perhaps not surprising, given the inconsistent findings for these behaviors even in the hours after disbudding. Although tail movements are associated with the immediate response during the procedure (Morisse et al., 1995; Graf and Senn, 1999), only one study has reported that they are indicative of postoperative pain (Heinrich et al., 2010). Transitions either become more common or do not change after disbudding with a hot-iron (Morisse et al., 1995; Stilwell et al., 2012) or caustic paste (Vickers et al., 2005; Winder et al., 2017). One study has reported less grooming after hot-iron disbudding (Morisse et al., 1995), but others have not been able to replicate this result (Doherty et al., 2007; Bates et al., 2019). Finally, bucks/jumps/kicks were rare in our study, but others have observed both fewer bucks (Mintline et al., 2013) and more hindleg kicks (Grondahl-Nielsen et al., 1999) after hot-iron disbudding compared with controls. These mixed results may arise from differences in definitions, sample size, sampling methodologies, and calf management practices, as well as the fact that these behaviors can be expressions of many different moti- 
vations besides pain (e.g., play, hunger, fly avoidance, temperature regulation). For example, Mintline et al. (2013) asked explicit questions about how locomotor play changed in response to disbudding and designed their experiment accordingly: calves had social companions and a relatively large, long "play pen" with deep straw bedding, all of which are known to increase play (Mintline et al., 2013) and were absent from our current work.

The frequencies of head shakes, ear flicks, and tail flicks in the present study were higher than those reported in the first few hours after hot-iron disbudding. Others have observed 31 or fewer head shakes per hour (Morisse et al., 1995; Graf and Senn, 1999; Heinrich et al., 2010; Stilwell et al., 2012; Huber et al., 2013), 10 or fewer ear flicks per hour (Heinrich et al., 2010; Stilwell et al., 2012; Huber et al., 2013), and 24 tail flicks per hour (Heinrich et al., 2010) within the first day after disbudding. This discrepancy may be explained by the fact that these behaviors are also used to avoid flies (Eicher and Dailey, 2002), which were present during this experiment but could not be quantified from video. Behaviors not typically associated with fly avoidance (i.e., head rubs, head scratches, grooming, transitions) showed comparable frequencies to those previously reported in calves (Morisse et al., 1995; Heinrich et al., 2010; Huber et al., 2013).

\section{Limitations and Other Considerations}

It is possible that lidocaine numbed calves to the presence of flies landing on their heads. This may explain why they shook their heads less and tended to flick their ears less while the anesthesia was active, although it does not explain the higher frequency of head rubs. Repeating this study with a sham-disbudded group that received lidocaine would address this possibility. We were unable to include such a group in the current study due to limitations in time and the number of available animals.

Our initial administration of $6.6 \mathrm{~mL}$ of buffered lidocaine yielded insufficient nerve blocks, so we increased our initial amount to $8.8 \mathrm{~mL}$, adding another $2.2 \mathrm{~mL}$ if a pinprick response occurred after the first administration. These dosages are higher than what is typically used for cornual nerve blocks (3-6 mL/horn; Stock et al., 2013), although studies rarely specify whether the lidocaine was buffered with sodium bicarbonate, which increases the volume injected by $10 \%$. The nerve block's anesthetic effect also subsided sooner than the duration of action reported in non-disbudded calves (107 to 512 min; Fierheller et al., 2012). In our study, the person administering the blocks achieved $>95 \%$ efficacy with the $5.5 \mathrm{~mL}$ given before disbudding, so inappropriate technique was an unlikely factor for the reduced efficacy $11 \mathrm{~d}$ later. Lidocaine works by blocking sodium channels, which transmit noxious information to the central nervous system. Following injury, sodium channels accumulate, contributing to hypersensitivity around the wound (Devor, 2006). Indeed, disbudding wounds are more sensitive to mechanical stimulation than uninjured horn buds throughout healing (Adcock and Tucker, 2018a; Casoni et al., 2019). Thus, we hypothesize that the reduced efficacy of the nerve block may have been due to the potentially increased density of sodium channels and hypersensitivity after disbudding.

\section{CONCLUSIONS}

Calves given lidocaine $11 \mathrm{~d}$ after disbudding exhibited behavioral changes consistent with a reduction in ongoing pain while the wounds were numb, followed by a return of sensation as the anesthesia wore off. These results add to a growing body of evidence that pain persists for weeks after disbudding and highlight the need for research on longer-acting analgesics or the uptake of non-painful alternatives.

\section{ACKNOWLEDGMENTS}

We thank University of California Davis Dairy Facility manager Doug Gisi, assistant manager Maria Patino, and the dairy interns for animal care and support. We are grateful to Emily Schall (University of California Davis) for assisting with data collection. This study was supported by USDA Multistate Research Project NC1029. We gratefully acknowledge the infrastructure support of the Department of Animal Science, College of Agricultural and Environmental Sciences, and the UC Davis California Agricultural Experiment Station. The authors declare that there are no conflicts of interest.

\section{REFERENCES}

Adcock, S. J. J., and C. B. Tucker. 2018a. The effect of disbudding age on healing and pain sensitivity in dairy calves. J. Dairy Sci. 101:10361-10373. https://doi.org/10.3168/jds.2018-14987.

Adcock, S. J. J., and C. B. Tucker. 2018b. Painful procedures: When and what should we be measuring? Pages 157-198 in Advances in Cattle Welfare. C. B. Tucker, ed. Woodhead-Elsevier, Duxford, UK. https://doi.org/10.1016/B978-0-08-100938-3.00008-5.

Adcock, S. J. J., and C. B. Tucker. 2020. Conditioned place preference reveals ongoing pain in calves 3 weeks after disbudding. Sci. Rep. 10:3849. https://doi.org/10.1038/s41598-020-60260-7.

Adcock, S. J. J., S. K. Vieira, L. Alvarez, and C. B. Tucker. 2019. Iron and laterality effects on healing of cautery disbudding wounds in dairy calves. J. Dairy Sci. 102:10163-10172. https://doi.org/10 .3168/jds.2018-16121.

Bates, A. J., M. A. Sutherland, F. Chapple, S. K. Dowling, A. P. Johnson, B. Saldias, and J. Singh. 2019. A new method of administer- 
ing local anesthesia for calf disbudding: Findings from a comparative on-farm study in New Zealand. J. Dairy Sci. 102:2492-2506. https://doi.org/10.3168/jds.2018-15033.

Casoni, D., A. Mirra, M. R. Suter, A. Gutzwiller, and C. Spadavecchia. 2019. Can disbudding of calves (one versus four weeks of age) induce chronic pain? Physiol. Behav. 199:47-55. https://doi.org/ 10.1016/j.physbeh.2018.11.010.

Cepeda, M. S., A. Tzortzopoulou, M. Thackrey, J. Hudcova, P. Arora Gandhi, and R. Schumann. 2010. Adjusting the $\mathrm{pH}$ of lidocaine for reducing pain on injection. Cochrane Database Syst. Rev. 12:CD006581. https://doi.org/10.1002/14651858.CD006581.pub2.

Devor, M. 2006. Sodium channels and mechanisms of neuropathic pain. J. Pain 7:S3-S12. https://doi.org/10.1016/j.jpain.2005.09 .006 .

Doherty, T. J., H. G. Kattesh, R. J. Adcock, M. G. Welborn, A. M. Saxton, J. L. Morrow, and J. W. Dailey. 2007. Effects of a concentrated lidocaine solution on the acute phase stress response to dehorning in dairy calves. J. Dairy Sci. 90:4232-4239. https://doi .org/10.3168/jds.2007-0080.

Eicher, S. D., and J. W. Dailey. 2002. Indicators of acute pain and fly avoidance behaviors in Holstein calves following tail-docking. J. Dairy Sci. 85:2850-2858. https://doi.org/10.3168/jds.S0022 -0302(02)74372-5.

Faulkner, P. M., and D. M. Weary. 2000. Reducing pain after dehorning in dairy calves. J. Dairy Sci. 83:2037-2041. https://doi.org/10 .3168/jds.S0022-0302(00)75084-3.

Fierheller, E. E., N. A. Caulkett, D. B. Haley, D. Florence, and L. Doepel. 2012. Onset, duration and efficacy of four methods of local anesthesia of the horn bud in calves. Vet. Anaesth. Analg. 39:431-435. https://doi.org/10.1111/j.1467-2995.2012.00717.x.

Friard, O., and M. Gamba. 2016. BORIS: A free, versatile open-source event-logging software for video/audio coding and live observations. Methods Ecol. Evol. 7:1325-1330. https://doi.org/10.1111/ 2041-210X.12584.

Graf, B., and M. Senn. 1999. Behavioural and physiological responses of calves to dehorning by heat cauterization with or without local anaesthesia. Appl. Anim. Behav. Sci. 62:153-171. https://doi.org/ 10.1016/S0168-1591(98)00218-4.

Grøndahl -Nielsen, C., H. B. Simonsen, J. Damkjer Lund, and M. Hesselholt. 1999. Behavioural, endocrine and cardiac responses in young calves undergoing dehorning without and with use of sedation and analgesia. Vet. J. 158:14-20. https://doi.org/10.1053/tvjl .1998 .0284

Heinrich, A., T. F. Duffield, K. D. Lissemore, and S. T. Millman. 2010. The effect of meloxicam on behavior and pain sensitivity of dairy calves following cautery dehorning with a local anesthetic. J. Dairy Sci. 93:2450-2457. https://doi.org/10.3168/jds.2009-2813.

Huber, J., T. Arnholdt, E. Möstl, C. C. Gelfert, and M. Drillich. 2013. Pain management with flunixin meglumine at dehorning of calves. J. Dairy Sci. 96:132-140. https://doi.org/10.3168/jds.2012-5483.

Jimenez, R. E., S. J. J. Adcock, and C. B. Tucker. 2019. Acute pain responses in dairy calves undergoing cornual nerve blocks with or without topical anesthetic. J. Dairy Sci. 102:3431-3438. https:// doi.org/10.3168/jds.2018-15445.

Lenth, R. V. 2018. emmeans: Estimated marginal means, aka least squares means. R package version 1.3.0. Accessed Nov. 1, 2018. https://CRAN.R-project.org/package=emmeans.

McMeekan, C., K. J. Stafford, D. J. Mellor, R. A. Bruce, R. N. Ward, and N. Gregory. 1999. Effects of a local anaesthetic and a nonsteroidal anti-inflammatory analgesic on the behavioural responses of calves to dehorning. N. Z. Vet. J. 47:92-96. https://doi.org/10 $.1080 / 00480169.1999 .36120$.

McMeekan, C. M., D. J. Mellor, K. J. Stafford, R. A. Bruce, R. N. Ward, and N. G. Gregory. 1998. Effects of local anaesthesia of 4 to 8 hours duration on the acute cortisol response to scoop dehorning in calves. Aust. Vet. J. 76:281-285. https://doi.org/10.1111/j.1751 -0813.1998.tb10160.x.

Melzack, R. 1996. Gate control theory. Pain Forum 5:128-138. https:/ /doi.org/10.1016/S1082-3174(96)80050-X.
Mintline, E. M., M. Stewart, A. R. Rogers, N. R. Cox, G. A. Verkerk, J. M. Stookey, J. R. Webster, and C. B. Tucker. 2013. Play behavior as an indicator of animal welfare: Disbudding in dairy calves. Appl. Anim. Behav. Sci. 144:22-30. https://doi.org/10.1016/j .applanim.2012.12.008.

Moon, S., S.-J. Lee, E. Kim, and C.-Y. Lee. 2012. Hypoesthesia after IAN block anesthesia with lidocaine: Management of mild to moderate nerve injury. Restor. Dent. Endod 37:232-235. https://doi .org/10.5395/rde.2012.37.4.232.

Morisse, J. P., J. P. Cotte, and D. Huonnic. 1995. Effect of dehorning on behaviour and plasma cortisol responses in young calves. Appl. Anim. Behav. Sci. 43:239-247. https://doi.org/10.1016/0168 $-1591(95) 00569-\mathrm{E}$.

R Core Team. 2017. R: A Language and Environment for Statistical Computing. R Foundation for Statistical Computing, Vienna, Austria.

Stewart, M., J. M. Stookey, K. J. Stafford, C. B. Tucker, A. R. Rogers, S. K. Dowling, G. A. Verkerk, A. L. Schaefer, and J. R. Webster. 2009. Effects of local anesthetic and a nonsteroidal antiinflammatory drug on pain responses of dairy calves to hot-iron dehorning. J. Dairy Sci. 92:1512-1519. https://doi.org/10.3168/jds.2008-1578.

Stilwell, G., R. C. de Carvalho, M. S. Lima, and D. M. Broom. 2009. Effect of caustic paste disbudding, using local anaesthesia with and without analgesia, on behaviour and cortisol of calves. Appl Anim. Behav. Sci. 116:35-44. https://doi.org/10.1016/j.applanim 2008.06.008.

Stilwell, G., M. S. Lima, R. C. Carvalho, and D. M. Broom. 2012. Effects of hot-iron disbudding, using regional anaesthesia with and without carprofen, on cortisol and behaviour of calves. Res. Vet. Sci. 92:338-341. https://doi.org/10.1016/j.rvsc.2011.02.005.

Stock, M. L., S. L. Baldridge, D. Griffin, and J. F. Coetzee. 2013. Bovine dehorning: Assessing pain and providing analgesic management. Vet. Clin. North Am. Food Anim. Pract. 29:103-133. https: //doi.org/10.1016/j.cvfa.2012.11.001.

Summer, G. J., K. A. Puntillo, C. Miaskowski, P. G. Green, and J. D. Levine. 2007. Burn injury pain: The continuing challenge. J. Pain 8:533-548. https://doi.org/10.1016/j.jpain.2007.02.426.

Sutherland, M. A., D. J. Mellor, K. J. Stafford, N. G. Gregory, R A. Bruce, and R. N. Ward. 2002. Cortisol responses to dehorning of calves given a 5 -h local anaesthetic regimen plus phenylbutazone, ketoprofen, or adrenocorticotropic hormone prior to dehorning. Res. Vet. Sci. 73:115-123. https://doi.org/10.1016/S0034 -5288(02)00005-X.

Sylvester, S. P., K. J. Stafford, D. J. Mellor, R. A. Bruce, and R. N. Ward. 2004. Behavioural responses of calves to amputation dehorning with and without local anaesthesia. Aust. Vet. J. 82:697700. https://doi.org/10.1111/j.1751-0813.2004.tb12162.x.

USDA (United States Department of Agriculture). 2018. Health and Management Practices on U.S. Dairy Operations, 2014. Report 3. USDA-Animal Plant Health Inspection-Veterinary ServicesCenter for Epidemiology and Animal Health-National Animal Health Monitoring System, Fort Collins, CO. Accessed June 12, 2018. https://www.aphis.usda.gov/animal_health/nahms/dairy/ downloads/dairy14/Dairy14_dr_PartIII.pdf.

Vickers, K. J., L. Niel, L. M. Kiehlbauch, and D. M. Weary. 2005. Calf response to caustic paste and hot-iron dehorning using sedation with and without local anesthetic. J. Dairy Sci. 88:1454-1459. https://doi.org/10.3168/jds.S0022-0302(05)72813-7.

Winder, C. B., S. J. LeBlanc, D. B. Haley, K. D. Lissemore, M. A. Godkin, and T. F. Duffield. 2017. Clinical trial of local anesthetic protocols for acute pain associated with caustic paste disbudding in dairy calves. J. Dairy Sci. 100:6429-6441. https://doi.org/10 $.3168 /$ jds.2017-12724.

\section{ORCIDS}

Sarah J. J. Adcock @ https://orcid.org/0000-0003-0227-5369 Cassandra B. Tucker ำ https://orcid.org/0000-0002-6014-444X 